\title{
Workforce Modernisation in Police Detention Suites: The Dilemmas of Outsourcing in Public Services
}

\section{Authors: Geoff Heath, Rob C Mawby, and Lynne Walley}

Word count: $\quad$ Abstract $=148$

Text excluding references $=3,443$

\section{Author details:}

Geoff Heath, Lecturer in Public Sector Accounting, School of Economic and Management Studies, Keele University, Staffordshire, ST5 5BG, UK. Email: g. heath@keele.ac.uk.

Rob C Mawby, Reader in Criminal J ustice, Centre for Criminal Justice Policy and Research, Birmingham City University, UK.

Lynne Walley, Head of Centre for Professional Management, Staffordshire University, UK. 


\begin{abstract}
This article draws upon our experience of evaluating a project funded by the Home Office's workforce modernisation programme, which concerned the outsourcing of the detention officer role in an English police force. The efficiency and effectiveness of the project were established, but questions about accountability, equity and sustainability were also raised. These findings complement the literature on outsourcing in the public sector. Studies suggest that the issues associated with the application of outsourcing include the extent to which cost savings are achieved, the causes of such savings and the implications of this for quality and equity. Outsourcing may be seen as a relatively unproblematic way of increasing efficiency in the public sector from some theoretical perspectives, but that is disputed. Our work contributes to the debate by presenting further evidence that, while outsourcing can produce significant savings, this is neither straightforward to achieve nor without awkward side effects.
\end{abstract}

\title{
Introduction
}

The outsourcing of public services is topical and controversial. In this article we reflect on our experience of evaluating a Home Office funded project, which concerned the outsourcing of the detention officer role in two detention suites in a county police force. (For a fuller discussion, see Mawby et al., forthcoming.)

Outsourcing occurs when a contract is awarded 'out of house', normally following a process of competitive tendering. Competitive tendering involves inviting tenders to deliver services from a range of providers. In public services, this may encompass private sector providers, 'third sector' providers and other public sector organisations. Usually the contract will be awarded to the lowest bidder. Public ownership of assets is maintained, but the provision of the service and thus the management of these assets is transferred. This will be subject to a contract and for a specific period of time.

Outsourcing may be justified from theoretical perspectives which stress the role of competition, incentives and the profit maximisation motive in the efficient allocation of resources. However, there are other theoretical perspectives which cast doubt on the universal and automatic superiority of outsourcing over other ways of organising the delivery of public services.

In evaluating outsourcing projects, therefore, as with all public sector projects, it is necessary to assess whether satisfactory value for money has been achieved. This brings economy, efficiency and effectiveness into the evaluation. It is desirable, however, to also take into account other factors such as equity (i.e. the fair distribution of resources) when evaluating projects (Heath, 2003).

The existing literature suggests that the 'wicked' issues around outsourcing include: the extent of any cost savings; the source of these savings; the effective management of contracting; and the changing 
nature of accountability. (See, for example, Prager, 1994; Jensen and Stonecash, 2005; Mulgan, 2006). Although the project we evaluated proved successful in terms of its objectives, some of these issues were also highlighted; particularly equity and accountability.

\section{Theoretical Perspectives}

Before outlining the project and its evaluation, we turn briefly to theoretical perspectives on outsourcing. Efficiency gains from outsourcing are variously attributed to competition, incentives and the change in the nature of ownership. These claims are derived from public choice theory, in which it is argued that human behaviour is based on selfishness rather than altruism; that bureaucrats will pursue their own interests by maximising their budgets rather than spending efficiently; and that incentives are required to direct them towards the public interest. Such incentives are said to be applied most effectively under competitive pressures and private ownership. Contracting out, therefore, would offer a remedy for the perceived problems of bureaucracy (Boyne, 1998).

However, there is no evidence that public sector provision is inherently less efficient than the provision of public services in the private sector (Prager, 1994); while there is evidence that public servants are motivated by intrinsic rewards rather than 'high powered' incentives (J ensen and Stonecash, 2005). Indeed, critics of public choice theory have argued persuasively that it both exaggerates bureaucrats' aims for budget maximisation and plays down the constraints on their ability to achieve this (Boyne, 1998).

It is particularly interesting here to pick out some relevant criticisms of public choice theory derived from other fields of economics. Organisational economics stresses the transactions costs associated with drawing up contracts, monitoring performance and controlling contractors, which may outweigh any gains from the contracting process. Moreover, it is not possible (and certainly not cost-effective) to cover all contingencies in contracts, so they are necessarily incomplete, thus allowing opportunistic behaviour. Principal-agent theory argues that agents pursue their own interests rather than those of their principals and that this is facilitated in contractual relationships, because of increased information asymmetry. Relational contracting theory holds that competitive tendering reduces trust between principals and agents; but the use of behavioural norms, such as mutual trust, can lead to greater effectiveness without the costs of close scrutiny of performance.

Furthermore, contingency theory would suggest that the success of outsourcing depends on the coming together of various factors to support it. Prager (1994) argues that the most important contingent factors are the potential for economies of scale and scope, organisational restructuring, competition, and the capability to manage contracts effectively. If these are not present, outsourcing is unlikely to be effective. Moreover, outsourcing is not necessarily the only option even under these circumstances. Entering into consortia with other public sector 
organisations, for instance, could give economies of scale and scope and facilitate re-organisation.

\section{The Project}

The case to which we refer concerned the outsourcing of the detention officer role in two police station detention suites in one Basic Command Unit of an English county police force between 2004 and 2006. The force successfully submitted a bid to the Home Office's Workforce Modernisation Implementation Fund which financed a number of experimental projects aimed at increasing the effectiveness of police officer deployment. Demonstration sites were established in which working practices are being remodelled so that police support staff can take up designated roles previously carried out by police officers. Mixed teams are created, with tasks assigned according to skills, expertise and specialist powers. Efficiencies gained by the new ways of working are reinvested into the front line (Home Office, 2007).

The project was to create ten front-line policing posts by outsourcing the gaoler role. It was decided at the project planning phase to opt for outsourcing rather than using police staff on the grounds of expense. Funding was secured over two years and 'Outsourced plc' secured the contract to provide the detention services. Following a short training period, Outsourced plc employees, known as Civilian Detention Officers (CDOs) took over from the gaolers, each being assigned to work with a police custody sergeant.

The objectives of the project were: (1) to maintain the level of care to detainees within the detention suites and to reduce the number of confrontational situations through the introduction of non-police personnel; (2) to release the equivalent of ten police officer posts from custody to front-line roles; (3) to reduce abstractions of police officers from other duties to cover for absent detention officers; and (4) to generate efficiency savings of $£ 200,000$ per annum.

\section{The Evaluation}

To assess the project's achievements against these objectives, over a period of twenty-two months we undertook process and outcome evaluations that drew on qualitative and quantitative methods and a costing exercise.

\section{Detention suite service levels}

To assess service levels in the detention suites, our qualitative research included observations, interviews and analysis of comments from the reports of Independent Custody Visitors. These activities complemented quantitative work that included monitoring the number of complaints preand post-outsourcing. In addition we conducted pre- and postimplementation stakeholder surveys with visitors to the two detention 
suites. From this data, we concluded that there was no decline in the quality of operations in the suites from an already high standard.

\section{Impact on front-line policing}

The project aimed to impact favourably on front-line policing in two ways. First, by transferring staff from gaoler to operational posts and, secondly, by removing the necessity to take officers from front line duties to cover staff absences in the detention suites.

The gaolers did not take up the front line posts themselves. Instead a complex chain of 'displacements' was needed to fill them. Nevertheless, ten new posts were identified, which were filled between November 2004 and April 2005. Discussions with local managers revealed that significant benefits were anticipated initially; but organisational changes over time and departments carrying permanent vacancies, meant it did not prove possible to positively identify benefits attributable solely to the project. We were, therefore, unable to demonstrate the effects of outsourcing the detention suites in terms of strengthening the front-line.

However, as a result of outsourcing, front-line resources were not reduced by the abstraction of operational officers from other duties to cover staff absences in the detention suites. Outsourced plc were required to provide their own cover when their employees were absent. If they were unable to do so, they had to pay the overtime of police officers who were recalled from rest days, rather than abstracting on-duty police officers.

\section{Diversity of the workforce}

A recurring theme of police reform has been that the staffing of police organisations should become more diverse (Macpherson, 1999; Rowe, 2007). Accordingly the Home Office was interested in the diversity aspects of the workforce modernisation projects. Data provided by Outsourced plc confirmed that the ethnic diversity of the work force had not changed following outsourcing: it remained overwhelmingly 'White British'. However, $51 \%$ of the CDOs were female and $44 \%$ were aged below thirty, which contrasted with the previous gaolers who were mature males.

Increasing diversity is seen as a benefit in itself, but the force also wished to test whether civilian detention officers were less likely to be involved in confrontational situations with detainees. The pre-project confrontation level was already so low that it was unlikely it would reduce significantly, although conceivably it could have increased. In practice, very few such situations occurred, indicating that the level differed little from when the job was undertaken by police officers.

\section{Efficiency and Effectiveness}

To evaluate the value for money of the project, we monitored the contract costs, together with the direct and indirect costs of contract management. 
We also identified the costs involved in redeploying police officers to the front-line. The cost-consequences analysis (Heath, 2003) utilised Home Office guidelines for conducting economic evaluations (Dhiri and Brand, 1999). We estimated that the outsourcing had realised annualised net savings of around $£ 250,000$.

However, it had been force practice to employ experienced officers, towards the top of the pay scale, as gaolers. As this policy influenced the extent of the savings achieved through outsourcing, the cost of using 'average' officers, i.e. those at the mid-point of the scale, was also estimated. This had the effect of reducing the annual savings to around $£ 190,000$. Nevertheless, the project achieved both significant savings and significant benefits.

\section{Sustainability and Equity}

The gains in efficiency were not unproblematic. A strong argument in favour of civilianisation or outsourcing is that detention suites are not a prestigious posting for police officers. In itself, this might reduce the replicability of the project's results if applied to more popular posts. Nevertheless, it seemed reasonable to suggest that the introduction of dedicated CDOs in permanent posts would bring stability and resilience to the detention suite work force. However, it became clear that a significant amount of overtime was being incurred as a result of CDO absences and there must be some risk that Outsourced plc would not wish to carry these penalties indefinitely.

Moreover, it was apparent that Outsourced plc offered a basic remuneration package, and there was discontent among the CDOs concerning their terms and conditions of employment. As staff retention and morale are important to the maintenance of the teamwork that the detention suites depend on, we had wished to track CDO retention levels. Unfortunately, the necessary data was not made available. However, although we were not in a position to establish whether there was a link between the CDOs' dissatisfaction and the extent of overtime being worked, Midshire Police took these matters seriously. We were told that 'robust scenario planning' existed in the event that Outsourced plc withdrew from the contract.

This development also points to the important issue of equity. It might be argued that the project contributed to increasing equity via the greater diversity of the work force. Set against this, however, must be the changing nature of the posts in the detention suites; whereby semiprofessionalised staff with generous remuneration and conditions of service were replaced by contract workers who have lower pay, inferior terms and limited prospects of career development. It is worth recalling here that the alternative of civilianisation was rejected before the project commenced. This would have generated less, but not negligible, savings while providing CDOs with better wages, conditions and prospects. 


\section{Discussion}

The literature suggests that analysing changes in expenditure following outsourcing is not straightforward. According to Jensen and Stonecash (2005), outsourcing does result in reductions in public spending overall, but the extent of cost reduction varies widely and seems dependent on individual circumstances. Moreover, the amount of savings does not seem in line with the more ambitious claims for outsourcing. Furthermore, carrying out research on this topic is fraught with methodological difficulties. For example, studies may omit the costs of managing the tendering and contracting process in their evaluations of outsourcing projects. (See Boyne, 1998, for a discussion of such issues). Cost savings associated with outsourcing may be explained by increased efficiency. However, a number of hypotheses have been put forward which propose more disturbing explanations for the savings.

The quality shading hypothesis suggests that the cost reductions from tendering simply reflect deterioration in the quality of service after outsourcing, especially where quality is difficult to measure. There is some evidence for quality shading in the literature, but declines in quality may result from inadequate specification or unsatisfactory monitoring of performance, which suggests quality shading is preventable ( $J$ ensen and Stonecash, 2005). Against this, however, it may be argued that poor or misdirected performance is easier to correct in a hierarchical than a contractual relationship. Also where quality control is more effective, tendering may become less attractive.

The re-distribution hypothesis holds that savings are achieved from deteriorating conditions of employment rather than by more efficient utilisation of resources. Thus savings from outsourcing would represent a transfer of economic rent from workers to corporations. In that case, any increases in efficiency are linked to decreases in equity and there is not necessarily a gain in social welfare overall. A number of studies identify increases in the intensity of workers' efforts and reductions in their pay and conditions associated with outsourcing and some suggest these reductions were the major element in the overall cost savings ( $J$ ensen and Stonecash, 2005).

The non-persistence of savings hypothesis suggests that cost reductions may be achieved initially, but that contractors will attempt to pressure purchasers to re-negotiate later, so that savings decrease over time. As contracts are necessarily incomplete, this may be relatively easy to achieve, especially as there would be switching costs. 'Low balling' is where low bids are submitted deliberately to win a tender with the intention of re-opening negotiations later (Prager, 1994). The extent of low balling is difficult to establish empirically, however, as it would require evidence about intent, which is unlikely to be divulged. Moreover, contractors may make genuine mistakes in bidding or specifications may be poorly drawn up and disguise the resources needed (Jensen and Stonecash, 2005). Nevertheless, whatever the cause, the existence of erosion in savings, following re-negotiation of contracts, is recognised in the literature. 
The management of contracting is a significant factor in determining the success or failure of individual outsourcing projects, but is far from straightforward. Prager (1994) suggests that significant issues arise both in terms of choosing contractors and monitoring contracts. At the selection stage, for example, there are problems of how to prevent collusion between bidders; how to design the contract to best effect; and whether to include an element of judgement in awarding the contract, rather than awarding to the lowest bidder. This should avoid the problem of low balling, but builds scope for corruption into the process (Prager, 1994). At the monitoring stage, it is necessary to have sufficient capability and capacity for both financial auditing and technical monitoring, which incurs (potentially onerous) costs of scrutiny. Therefore, as Prager (1994) says, where the combined total of the contract price and the cost of the contract management exceed the cost of in-house production, contracting out is inappropriate.

It may be also argued that outsourcing reduces public accountability. Cameron (2004) contends that the introduction of private firms into the provision of public services leads to a lack of clarity as to who is responsible for what and, therefore, accountable. Thus '... the demonstration of accountability concepts (such as transparency, equity of treatment and probity of public resources ...), has the potential to become clouded...' (Cameron, 2004, p.64).

Mulgan (2006) considers that there are two contrasting views of public accountability under outsourcing: (1) Governments remain accountable for the services they buy (even though no longer responsible for how they are delivered) and more detailed specification of service outputs in contracts enhances this; and (2) Contractors are not subject to the same range of accountability mechanisms as government departments, so accountability declines. He argues that these two competing perspectives can be reconciled by recognising claims that accountability has not changed are 'rhetorical'; i.e. governments have accepted that their citizens will not allow ultimate responsibility for service delivery to be offloaded on to the contractors. Nevertheless, this only applies to results (defined broadly) and not to inputs and processes. Commercial confidentiality has led to significantly less transparency concerning this. Intriguingly, he gives as an example of this the lack of accountability of public sector purchasers for conditions of employment in their contractors.

Our evaluation demonstrated a considerable reduction in costs resulting from outsourcing, even after the costs of managing the tendering and contracting process were taken into account. Moreover, the management of these processes in itself seemed effective. Significantly, there was no evidence of quality shading: the quality of operations in the detention suites was maintained or even improved. We were not in a position to monitor whether the cost savings persisted over time, although it would have been fascinating to do so.

At the same time, however, the savings were undoubtedly attributable largely to a decline in employees' pay and conditions. In this case, there was no obvious scope for, say, increasing productivity or substituting 
capital for labour, and less expensive workers simply replaced more expensive ones. It might be argued that the previous employment of police officers in this role represented poor value for money when it was subsequently carried out more than satisfactorily by the CDOs. However, it is also relevant that the option of employing police support staff was rejected on cost grounds. It may also be considered that the decline in terms of employment was compensated, to some extent, by the wider diversity of the work force. Nevertheless, important questions are raised concerning the trade-off between efficiency and equity. Indeed, there is something incongruous in the way a reduction in the imbalances of gender and age was accompanied by deterioration in conditions.

Finally, if we turn to accountability, we found no problems of control arising at an operational level, even though the CDOs were responsible both to the police sergeants in the detention suites and to their line managers at Outsourced plc. However, there was clearly a decline in process accountability along the lines argued by Mulgan, in that Midshire police was no longer accountable for the terms of employment of staff working as CDOs.

\section{Conclusion}

The literature suggests that outsourcing can give rise to worthwhile cost savings, but not in all cases and contingent factors are significant in determining the success of projects. The ability to manage the contracting process effectively is an important element in determining the outcome. The cause of cost savings could be increased efficiency. However, there is evidence that, in some cases, savings may arise from quality shading or from deterioration in workers' conditions of employment and remuneration. There is also evidence that savings may not persist at their original level over time. Again there is a strong argument that public accountability declines as a result of outsourcing, especially with regard to how services are delivered.

Our study demonstrated that this police outsourcing project achieved significant cost savings during the period of the evaluation without a decline in quality of service and created ten extra front line posts at a considerably lower cost than would otherwise have been possible. Moreover, the front-line was no longer weakened by abstractions and the diversity of the work force was enhanced. However, there were more concerning indications about the longer term sustainability of the project. Furthermore, our evaluation brought forward significant issues regarding equity and accountability. In doing so, it is in line with the literature in suggesting the dilemmas of outsourcing in public services. Thus it adds to a critique of theories which claim that outsourcing is an unproblematic means of improving public sector performance. 


\section{Acknowledgements}

We acknowledge the assistance and funding provided by the Home Office and Midshire Police that enabled the evaluation. The views expressed in this article are those of the authors and are not necessarily shared by the Home Office or Midshire Police.

An earlier version of the paper was presented at the $12^{\text {th }}$ Annual Dilemmas for Human Services International Conference at the University of East London in 2008. We thank the participants for their constructive comments.

\section{References}

Boyne, G.A. (1998). "Competitive Tendering in Local Government: A Review of Theory and Evidence." Public Administration 76: 695 - 712.

Cameron, W. (2004). "Public accountability; Effectiveness, Equity, Ethics." Australian Journal of Public Administration 63(4): 59-67.

Dhiri, S. and Brand, S. (1999). Analysis of Costs and Benefits: Guidance for Evaluators, Crime Reduction Programme Guidance Note 1. London: Home Office.

Heath, G. (2003). "Economic Analysis and the Evaluation of Police Service Projects: Clarification and Critique." Police Research and Management 6(1): 9-22.

Home Office (2007) Policing Policy e-bulletin, Issue 104 - July 2007. London: Home Office.

Jensen, P. and Stonecash, R. (2005). "Incentives and the Efficiency of Public Sector-Outsourcing Contracts." J ournal of Economic Surveys 19(5): 767-787.

Macpherson, Sir William (1999) The Stephen Lawrence Inquiry. cm 42621. London: HMSO.

Mawby, R.C., Heath, G. and Walley, L. (forthcoming). "Workforce Modernisation, Outsourcing and the 'Permanent Revolution' in Policing." Crime Prevention and Community Safety: an International J ournal.

Mulgan, R. (2006). "Government Accountability for Outsourced Services." Australian J ournal of Public Administration 65(2): 48-58.

Prager, J . (1994). "Contracting out Government Services; Lessons from the Private Sector." Public Administration Review 54: 176-184.

Rowe, M. (2007). Policing Beyond Macpherson: Issues in Policing, Race and Society. Cullompton: Willan. 